\title{
Research on Closed Residential Area Based on Balanced Distribution Theory
}

\author{
Si LAN, Ni FANG, Hai Peng LIN, Shi Qi YE \\ School of Information Science and Technology, Jinan University, Guangzhou, Guangdong 510000, China
}

\begin{abstract}
With the promotion of the street system, residential quarters and units of the compound gradually open. In this paper, the relationship between traffic flow and traffic flow is established for external roads, and the road resistance model is established by internal roads. We propose a balanced distribution model from the two aspects of road opening conditions and traffic flow inside and outside the district, and quantitatively analyze the impact of the opening and closing on the surrounding roads. Finally, it puts forward feasible suggestions to improve the traffic situation and optimize the network structure.
\end{abstract}

\section{Introduction}

February 21st, 2016, the State Council issues the "opinions" on further strengthening the administration of city planning and construction, saying views aroused widespread concern and discussion, in principle no longer closing residential construction, opening built-residential area and the unit compound gradually.

Although the open area may lead to security issues, the focus of the discussion is whether open area can achieve the optimization of network structure, improve the road capacity and traffic conditions. One view is that the enclosed residential cell destroys the urban road network structure, which is easy to cause traffic jams while the open cell will reduce the density of the road network.

\section{Model establishing}

This paper analyzes the influence of open area on the surrounding road traffic. The mathematical model of vehicle traffic includes the opening condition of the road and the balance to reach the driving time of the traffic inside and outside the residential cell.

\subsection{Cost - minimized Goal Planning Model}

It is indicated that the parameter $k$ is the total number of openings in the residential cell while $K$ is the maximum acceptable number, which satisfies the condition $k \leq K$. Because there is a certain amount of expenditure to be used for every opening, we should make the number of openings as few as possible.

Regarding the cost of per road section as the same, the total length of all sections which will be built should be as short as possible in terms of economy. Therefore, the goal is

$$
\min \sum_{i=1}^{k} \sum_{j=i+1}^{k} L_{i j}
$$

In which $L_{i j}$ represents the length of the road from the $i^{\text {th }}$ opening to the $j^{\text {th }}$ opening of the residential cell.

What's more, when the judging condition $Q_{\text {out }} \geq Q_{\text {max }}$ is true, in which $Q_{\text {out }}$ represents the traffic outside the residential cell and $Q_{\text {out }}$ represents the total carrying capacity of the lane, it is necessary to increase the number of openings to realize the diversion of vehicles.

\subsection{Time - balanced Distribution Model of Road Network}

Traffic assignment is to allocate the traffic demand to the traffic network according to a certain routing principle, so the traffic flow is got. If the time outside the residential cell is less than that through it, it is of little significance to open the cell. On the contrary, if most of the vehicles have chosen to pass through the cell after opening, then the cell will be in congestion and the traffic flow will be diverted into the outer road. Finally, all vehicles are randomly selecting paths, which can achieve the equilibrium state. At this time, the time spent on the road either inside or outside the cell is same.

According to the principle of time balance, a traffic assignment model of road network is established 


$$
\frac{x_{i j}}{v_{1}}=\frac{y_{i j}}{v_{2}}
$$

In which $x_{i j}$ means the length of the road outside from $i^{\text {th }}$ cell to $j^{\text {th }}$ cell; $y_{i j}$ means the length of the road inside; $v_{1}$ represents the driving speed outside the cell while $v_{2}$ represents the speed inside, both of which will be obtained in the following models.

\subsection{Speed-flow Relationship Model of Traffic Flow}

The traffic capacity of the external road is determined by the flow of the road. According to Greenshields theory, we can establish the speed-flow relationship model, as shown in figure 1 .

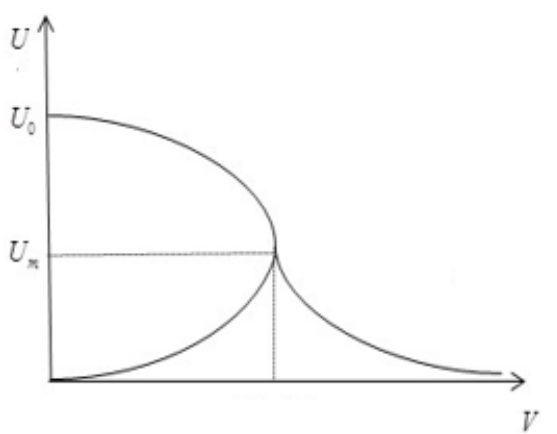

Figure 1 Schematic Diagram of Greenshields Theory time is

The average speed of the vehicle arriving in the unit

$$
v_{1}=U_{0} /\left(1+\frac{V}{C}\right)
$$

In which $U_{0}$ represents the average speed of vehicles when the traffic volume is zero and $\frac{V}{C}$ is a ratio about the actual traffic volume and the capacity of the road. In addition, according to the relationship between the whole and the part, we can get the following equation

$$
V / C=\sum V_{i} L_{i} / \sum C_{i} L_{i}
$$

In which $V_{i}$ means the distribution of traffic in section $i$ of the road network, $C_{i}$ means the traffic capacity of the section $i$ and $L_{i}$ means the length of section $i$.

However, the formula is obtained under the assumption that the vehicle uniformly dissipates, so two correction coefficients $\alpha$ and $\beta$ are quoted to obtain the traffic impedance model

$$
v_{1}=\frac{U_{0}}{1+\alpha\left(\frac{V}{C}\right)^{\beta}}
$$

To obtain a more accurate prediction result, we make
$V / C<0.8$ and $\gamma=1$. As a result, we get

$$
v_{1}=\alpha_{0} U_{s}\left(1+\gamma\left(\frac{V}{C}\right)^{\beta}\right)^{-1}
$$

In the model, $U_{s}$ is modified into the design speed and $\beta$ is a nonlinear function to $V / C$, which is expressed as

$$
\beta=\alpha_{2}+\alpha_{3}\left(\frac{V}{C}\right)^{3}
$$

Therefore, the speed-flow relationship model at any arbitrary level and traffic load is

$$
\left\{\begin{array}{l}
v_{1}=\frac{\alpha_{1} U_{s}}{1+\left(\frac{V}{C}\right)^{\beta}} \\
\beta=\alpha_{2}+\alpha_{3}\left(\frac{V}{C}\right)^{3}
\end{array}\right.
$$

\subsection{Road Resistance Function Model}

According to the traffic flow theory, the relationship $Q_{\text {in }}=\rho \cdot v$ will be obtained when the road facilities are in certain circumstances, in which $Q_{i n}$ is traffic flow inside the cell, $v$ is driving speed and $\rho$ is traffic density.

Under the assumption of continuous flow in the absence of interference, the model of road resistance function is

$$
\left\{\begin{array}{l}
t=\frac{L}{v} \\
v=\frac{v_{m}}{2}+\sqrt{\left(\frac{v_{m}}{2}\right)^{2}-\frac{Q_{i n} v_{m}}{1000 \rho_{m}}}
\end{array}\right.
$$

In which $L, v_{m}, \rho_{m}$ mean the length of the road, the smooth speed and the blocking density respectively.

In specific practical applications, the road traffic is usually intermittent, so we fix the processing model from four aspects of the interference, including intersection spacing, lane width, non-motor vehicles and pedestrians.

So we learned that $v_{m}=\mu_{1} \mu_{2} \mu_{3} \mu_{4} U_{s}$, in which $\mu_{1}, \mu_{2}, \mu_{3}, \mu_{4}$ are four correction coefficients of intersection of spacing influence, lane width influence, bike impact, pedestrian interference respectively.

Set the number of lanes to $n$, the average body length to $l$, the average block from the car to $l_{0}$. As the blocking density meets the condition $\rho_{m}=\frac{n}{l+l_{0}}$, the corrected one can be transferred into

$$
\rho_{m}=\frac{\mu_{1} \mu_{2} \mu_{3} \mu_{4} n}{l+l_{0}}
$$

According to the speed-flow relationship model and road resistance function model based on the traffic flow 
theory, we get the traffic balance inside and outside the district formula

$$
Q_{\text {in }}=Q_{\text {out }}
$$

\section{A Comparison of Roads in Two Exact Opening Conditions}

According to the classification of the cell 5.3.1, two types of cells closure are mainly discussed.

Figure 2 shows one residential cell whose opening level is not high in a medium-sized city. Assuming the external trunk road is two-way four-lane, it is known that the road designed speed is $40 \mathrm{~km} / \mathrm{h}$; capacity is $900 \mathrm{pcu} /$ $\mathrm{h}$; width of a lane is $3.75 \mathrm{~m}$. As for the cell we design, we make the two-lane road speed $40 \mathrm{~km} / \mathrm{h}$, capacity $900 \mathrm{pcu}$ $/ \mathrm{h}$, width of a lane $3.75 \mathrm{~m}$.

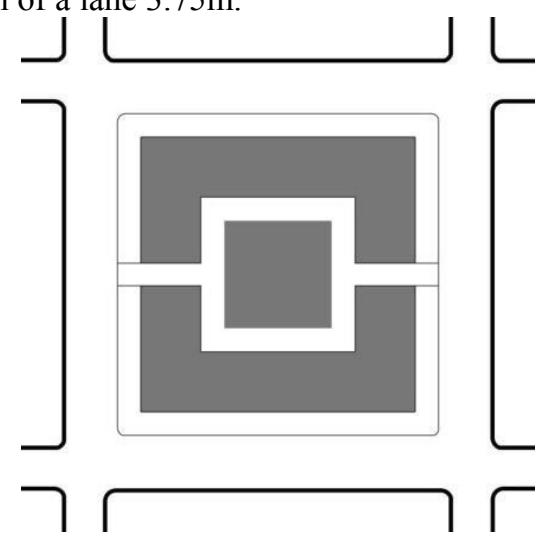

Figure 2 Cell Plot with an Angle Closure of 2

Base on the actual data of a residential cell in Changsha, the plot covers an area of a square, side length $500 \mathrm{~m}$, area 250000 , the resident population of about 15000 people. Two import and export corresponding to the external road traffic is $2000 \mathrm{pcu} / \mathrm{h}$ while the other two external roads' traffic is $800 \mathrm{pcu} / \mathrm{h}$. The two import and export flow data are shown in Table 1:

Table 1 Inlet and Outlet Flow Meter

\begin{tabular}{ccc}
\hline Models & Outlet (pcu/h) & Inlet (pcu/h) \\
\hline Non-Motor Vehicle & 136 & 66 \\
Bicycle & 224 & 59 \\
Pedestrian & 920 & 360 \\
\hline
\end{tabular}

Substituting data above into the model with MATLAB, and the result shows below:

$v_{1} \approx 36.67 \mathrm{~km} / \mathrm{h}, \quad v_{2} \approx 27.40 \mathrm{~km} / \mathrm{h}, \quad V=1142.86 \mathrm{pcu} / \mathrm{h}, \Delta Q=857.14 \mathrm{pcu} / \mathrm{h}$, $U_{1}=0.9, \quad \beta=13.34, \quad V_{m}=28.35 \mathrm{~km} / \mathrm{h}, \rho_{m}=0.1357$

We can see that after opening the cell, the density of the trunk road network increases and the external roads of the cell share the traffic flow of $857 \mathrm{pcu} / \mathrm{h}$ for the external ones, making the internal and external road load are about 1.2. In terms of speed, the open cell reduces the degree of peripheral lane congestion and improves the traffic speed. Although the speed of the internal lane is limited by the crowd and the width of the road, it reaches the requirements of the equilibrium theory in general, the speed of internal and external traffic can make the entire road network inside and outside keep relative balance, so it is reasonable and effective under the conditions of such a cell.

Figure 3 shows one cell whose opening level is high in a general city. Assuming the external trunk road is twoway six-lane, access to information that the road designs speed of $60 \mathrm{~km} / \mathrm{h}$, capacity of $1100 \mathrm{pcu} / \mathrm{h}$, width of a lane of $3.75 \mathrm{~m}$. As for the cell we design, we make it the twoway four-lane road speed of $40 \mathrm{~km} / \mathrm{h}$, capacity of $900 \mathrm{pcu}$ $/ \mathrm{h}$, width of a lane of $3.75 \mathrm{~m}$.

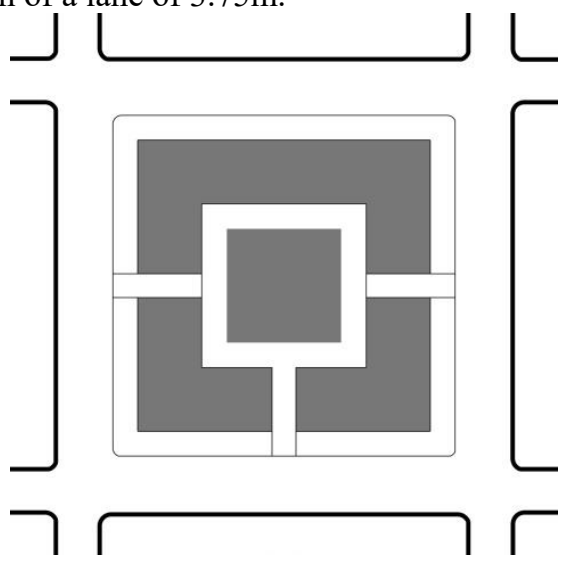

Figure 3 Cell Plot with an Angle Closure of 3

Substituting data above into the model with MATLAB, and the result shows below:

$v_{1} \approx 46.31 \mathrm{~km} / \mathrm{h}, \quad v_{2} \approx 34.52 \mathrm{~km} / \mathrm{h}, V=1152.32 \mathrm{pcu} / \mathrm{h}, \Delta Q=1047.38 \mathrm{pcu} / \mathrm{h}$, $U_{1}=0.863, \quad \beta=17.99, \quad V_{m}=35.76 \mathrm{~km} / \mathrm{h}, \rho_{m}=0.1987$

Base on the actual data of a cell in Changsha, the plot covers an area of a square, side length $600 \mathrm{~m}$, area 360000 $\mathrm{m}^{2}$, the resident population of about 20000 people. Three import and export corresponding to the main external road traffic is $2500 \mathrm{pcu} / \mathrm{h}$ while the other road's traffic is $1200 \mathrm{pcu} / \mathrm{h}$. The data about three import and export flow are shown in Table 2:

Table 2 Inlet and Outlet Flow Meter

\begin{tabular}{ccc}
\hline Models & Outlet (pcu/h) & Inlet (pcu/h) \\
\hline Non-Motor Vehicle & 164 & 85 \\
Bicycle & 240 & 67 \\
Pedestrian & 980 & 390 \\
\hline
\end{tabular}

We can see that after opening the cell, the density of the trunk road network increases and the external roads of the cell share the traffic flow of $1047 \mathrm{pcu} / \mathrm{h}$ for the external ones, making the internal and external road load are about 1.3 and 1.1 respectively. In terms of speed, the internal and speed almost reaches the requirements after the cell opens. The degree of congestion in the outer lane has alleviated and the traffic speed has increased, but still far less than the road design speed. Therefore, the external road is still congested and cannot make the road network balanced. That is to say, such an open residential cell settings cannot meet the requirements of the road network.

Compared the two types of cell models, we can conclude that the first one is a cell model whose opening degree is relatively low, roads within the cell are narrow, 
pedestrians are more and traffic capacity is poor, which is suitable for the condition that the traffic density is not too high; the second one is a cell model whose opening degree is relatively high, roads within the cell are wide and traffic density is not too large. However, the second cell model of the blocking density $\rho_{m}=0.1987>0.1357$, which shows the role of road traffic is not as well as the first category. Therefore, the selection of the cell model needs to be controlled on the external traffic flow within a certain range.

After analyzing the changes of different types of residential cells in different conditions, it is concluded that when the external traffic density does not exceed the limit, the effect of the open cell is positively correlated with the width of the road and the density of the road while it is negatively correlated with the population density and the number of non-motor vehicles. The open residential area can reduce the road load and blocking density, playing a role of sharing traffic flow, improving the road capacity and the traffic congestion.

\section{Conclusions}

When the external traffic density does not exceed the limit, the effect of the open cell is positively correlated with the road width and the trunk density while it is negatively correlated with the population density and the number of non - motor vehicles. Open residential area can reduce the road load and blocking density, share traffic flow, increase the road capacity and improve the traffic congestion.

\section{References}

1. Zhu F L. Research on Index System of Urban Traffic Congestion Measures[D]. Southeast University, 2006: 14-15.

2. Liu D, Lu F, Ma S Q. Screening and Determination of Evaluation Indexes for Comprehensive Evaluation
System of Road Traffic Safety[J]. Journal of Chinese People's Public Security University, 2005, 1: 42.

3. Yang G J, Zhao C Q, Zhang D H. Discussion on Evaluation Method of Urban Road Network Structure[J]. Journal of Zibo University, 2002, 4(1): 43-46.

4. Hu C, Zou Z Y, Mei Y N. Study on Evaluation Index System of Urban Road Network Planning[J]. Journal of Huazhong University of Science and Technology, 2006, 23: 98-99.

5. Liu M. Urban Transportation Continuous Equilibrium Network Design Based on Travel time Budget[D]. Southwest Jiao tong University, 2006: 44.

6. Wang W. Practical Speed-flow Relationship Model of Highway Traffic-flow $[\mathrm{J}]$. Journal of Southwest University, 2003, 33(4): 489-490.

7. Chang Y L, Wang X L, Zhang P. Speed-flow Relationship Model Based on the Upstream Traffic Volume of the Cosine Function Road[J]. Science Technology and Engineering, 2016, 16(11): 258.

8. Wang W, Zhang G H. Study on Road Resistance Function of Urban Road[J]. Journal of Southwest University for Nationalities, 1992, 11(3): 85-91.

9. Huang Y, Zhou W, Li J. Equilibrium of Traffic Flow in Transportation Network[J]. Journal of Southwest University for Nationalities, 2006, 32(2): 213-241.

10. Li X P. Urban Traffic Congestion Countermeasures-Opening Research of Enclosed Type District Traffic[D]. Henan University, 2014, 32(2): 46.

11. Qin G. Study of the Compatibility between Enclosed Residential Areas and Developing Transportation in Urban Areas[D]. Chang'an University Press, 2010: 51.

12. Gao Y. Research on Optimization Strategy of Residential Street Space Based on Traffic Microcirculation--for Example in Chengdu[J]. Southwest Jiao tong University, 2015: 20-21. 